\title{
Behavioral Parenting Interventions for Child Disruptive Behaviors and Anxiety: What's Different and What's the Same
}

\author{
Rex Forehand, Ph.D. ${ }^{1}$, Deborah J. Jones, Ph.D. ${ }^{2}$, and Justin Parent, B.A. ${ }^{1}$ \\ ${ }^{1}$ Department of Psychology, University of Vermont, Burlington, VT 05405 \\ ${ }^{2}$ Department of Psychology, University of North Carolina at Chapel Hill, NC 27599
}

\section{Abstract}

This paper reviews the role of parents in behavioral interventions with children's disruptive and anxiety problems. The evolution of interventions for these two types of problems differs, as has the role of parents in these interventions. In contrast to the central role of parents in the conceptualization and treatment of disruptive behaviors, parents have played a more varied and less prominent role in the conceptualization and treatment of children's anxiety. Furthermore, the literature involving parents in the treatment of children's anxiety indicates these interventions are more efficacious than control groups but not more efficacious than intervening with the child alone. Some limited evidence emerges for parenting as a mediator in the treatment of disruptive behaviors, but not of anxiety, where the role of parenting has rarely been measured. Implications for conceptualizing the role of parents in intervention programs for youth are discussed and directions for future research are delineated (e.g., collecting long term follow-up data, examine moderators of treatment response, develop programs for comorbid diagnoses).

\section{Keywords}

Behavioral Parent Interventions; Child Disruptive Behaviors; Child Anxiety

\begin{abstract}
Fifty years ago, Boardman (1962) described an alternative to the standard psychotherapeutic approach with children: "A 'short cut' involving the application of simple learning principles..." (p. 293) where the parents of 5-year old "Rusty" were taught procedures to change his rebellious behavior. Subsequently, in the mid to late 1960s, a group of clinical psychologists began programs of clinical research utilizing parents as the focus of intervention for the disruptive behaviors of their young children (Bernal, Durgee, Pruett, \& Burns, 1968; Hanf, 1969; Patterson \& Brodsky, 1966; Wahler, Winkel, Peterson, \& Morrison, 1965). Although the exact interventions utilized across these programs of research varied to some extent, the common factor was a focus on behavior, specifically changing parent behavior in order to change child behavior. This approach stood in contrast to the prevailing approach at the time: Play therapy and psychodrama with the child to resolve underlying anxiety that was causing the child's disruptive behavior (Patterson, 1982).
\end{abstract}

\footnotetext{
(C) 2012 Elsevier Ltd. All rights reserved.

Correspondence regarding this manuscript can be directed to: Rex Forehand, Dewey Hall, University of Vermont, Burlington, VT 05405; Rex.Forehand@uvm.edu.

Publisher's Disclaimer: This is a PDF file of an unedited manuscript that has been accepted for publication. As a service to our customers we are providing this early version of the manuscript. The manuscript will undergo copyediting, typesetting, and review of the resulting proof before it is published in its final citable form. Please note that during the production process errors may be discovered which could affect the content, and all legal disclaimers that apply to the journal pertain.
} 
The early efforts by Bernal, Hanf, Patterson, Wahler and their colleagues were initially constituted by case studies and uncontrolled group designs; however, these collective lines of research led to a major intervention approach evolving over the next 45 years. Behavioral parent training has now been carefully studied with rigorous research designs and is recognized as the leading intervention strategy for disruptive behaviors [i.e., Oppositional Defiant Disorder and Conduct Disorder (Eyberg, Nelson, \& Boggs, 2008)] (for reviews, see Chorpita, Daleiden, Ebesutani, Young, Becker, \& Starace, 2011; Dretzke et al., 2009; Eyberg et al., 2008; Lundahl, Risser, \& Lovejoy, 2006; Maughan, Christiansen, Jenson, Olympia, \& Clark, 2005; McMahon, Wells, \& Kotler, 2006; Serketich \& Dumas, 1996; Weisz \& Gray, 2008).

In contrast to working through parents to address disruptive behaviors, a different set of intervention strategies evolved in the early 1990s in the United States to address childhood anxiety: cognitive behavioral strategies implemented directly with the child (e.g., Kendall, 1994). The role of parents was noted early on in the treatment of anxiety in the United States (for an early conceptualization, see Kendall, Howard, \& Epps, 1988) and shown to be efficacious through single subject research methodology (Howard \& Kendall, 1996); however, interventions focused directly on the child, rather than indirectly effecting change through the parent (e.g., Flannery-Schroeder \& Kendall, 2000; Kendall, 1994; Kendall \& Southam-Gerow, 1996). In contrast, a more definitive role for parents in the treatment of child anxiety was recognized in the early 1990s among Australian researchers (Dadds, Heard, \& Rapee, 1992) and began to be incorporated into randomized trials as one arm of intervention by the mid-1990s (Barnett, Dadds, \& Rapee, 1996). Then, building upon their paper delineating a framework for family involvement (Ginsburg, Silverman, \& Kurtines, 1995), in the late 1990s, Silverman and her colleagues began to examine the role of parents in the treatment of children's anxiety in the United States (Silverman et al., 1999a, 1999b). As this literature has expanded, the role parents have played in the treatment of anxiety has varied substantially across studies (Barnish \& Kendall, 2005) and, as we will delineate later, is substantially different from and more varied than the consistent and central role parents have played in the treatment of disruptive behaviors.

The purpose of this paper is to review and contrast the literature examining the role of parents in behavioral treatment (not prevention) of children's disruptive behaviors and anxiety. We use the convincing literature for the role of parents in the treatment of disruptive behaviors as a backdrop for updating, expanding, and re-evaluating conclusions reached recently by others (Barnish \& Kendall, 2005; Breinholst, Esbjorn, Reinholdt-Dunne, \& Stallard, 2012; Kendall, Settipani, \& Cummings, 2012; Reynolds, Wilson, Austin, \& Hooper, 2012; Silverman, Pina, \& Viswesvaran, 2008) about the less frequently studied role of parents in the treatment of child anxiety. The goal is to identify similarities and differences in the role of parenting generally and relevant parenting behaviors specifically in the development and treatment of disruptive behavior and anxiety. By considering the state of the literature on parenting with both of these domains of child problems, we hopefully will facilitate communication across the two fields of study. If researchers and clinicians working with anxious children can learn from those working with disruptive children and vice versa, then the role of parenting in our conceptualization and treatment of child psychopathology will be enhanced.

To the best of our knowledge, this is the first effort to compare and contrast the role of parents in the etiology and treatment of these two types of child problems. We believe that such a comparison is critical for several reasons. First, both disruptive behaviors and anxiety are among the most common psychiatric disorders of children and primary reasons for the referral of children to mental health services (Hindshaw \& Lee, 2003; Silverman et al., 2008). Second, the two types of child problem behaviors exemplify the different roles of 
parents in the treatment of the broadband categories of child externalizing and internalizing problems.

We chose to focus on anxiety, rather than depression, and disruptive behaviors, rather than Attention Deficit Hyperactivity Disorder (ADHD), as representative of interventions with internalizing and externalizing problems, respectively, for two reasons. First, we located approximately six times the number of treatment studies for childhood anxiety than for childhood depression that met our criteria for inclusion. More definitive conclusions, in turn, can be reached when there are more studies to evaluate. Second, ADHD is an externalizing problem that also can be impacted by parent training (see Pelham \& Fabiano, 2008); however, unlike ODD and CD, ADHD is considered a "chronic disorder" (Pelham \& Fabiano, 2008, p. 2009) that, from our perspective and that of others (Pelham, 2008), is most often treated primarily with medication (stimulants) (e.g., Gureasko, DuPaul, \& Power, 2005; Pelham, 2012). Furthermore, by separating disruptive behaviors and ADHD, we are being consistent with DSM-IV-TR (APA, 2000) nosology (i.e., Attention-Deficit and Disruptive Behavior Disorders) and the 2008 special issue of the Journal of Clinical Child and Adolescent Psychology on Evidence-Based Psychosocial Treatments for Children and Adolescents edited by Silverman and Hinshaw.

It is important to point out that there are a range of parenting interventions available for the treatment of disruptive behaviors. As examples, some, but not most, are mastery based (i.e., a parent demonstrates a certain level of acquisition of one skill before moving to the next skill) (e.g., McMahon \& Forehand, 2003); some programs are conducted in groups (e.g., Webster-Stratton \& Herman, 2008), whereas others are conducted with individual families (e.g., McMahon \& Forehand, 2003); and some, but not all, programs rely extensively on modeling, roleplaying, and parent practice with the child while receiving feedback (e.g., McMahon \& Forehand, 2003). Similarly, there are a range of available parenting interventions for anxiety disorders which share similarities, but also are not identical. Some involve a focus on parental anxiety (e.g., Cobham, Dadds, \& Spense, 1998) whereas others do not (e.g., Silverman, Kurtines, Ginsburg, Weems, Lumpkin, \& Carmicheal, 1999); some are conducted primarily with the parent and child together (e.g., Silverman et al., 1999a), whereas others have separate sessions for the parent and the child (e.g., Spence, Donovan, \& Brechman-Toussaint, 2000); some are conducted primarily in groups (e.g., Silverman et al., 1999a) and others are conducted with individual families (e.g., Kendall, Hudson, Gosch, Flannery-Schroeder, \& Suveg, 2008). Our point is that there is heterogeneity within parenting interventions for each of these two types of child problems. Nevertheless, each intervention does engage the parent, at least to some extent, in the treatment of childhood problems and, in turn, will be reviewed here.

In the subsequent sections, we will consider the following topics pertaining to parents and how they have differed for the conceptualization and treatment of disruptive behaviors versus anxiety: (a) The role of parenting in their development; (b) the evolution of parenting interventions; (c) the specific roles of parents in the interventions; and (d) the specific parenting behaviors that have been targeted. Based on this review, we "accept" the conclusion of the numerous reviews already cited: A parent behavioral intervention is an efficacious approach for addressing child disruptive behaviors. When considered against this backdrop, we then consider the current state of the literature for parenting interventions with anxiety. We then review studies which have examined parenting as the mediator of child behavior change when a parenting intervention is implemented and conclude by delineating some areas of future research. 


\section{The Role of Parenting in the Development of Disruptive Behavior and Anxiety}

The dominant perspective on the development of disruptive behaviors is the early starter model (see McMahon \& Forehand, 2003), also known as child-onset type (Moffit et al., 2008), and a more recent derivative known as the cascade model (Dodge, Greenberg, \& Malone, 2008). The role of parenting is central to the development of disruptive behaviors in this model. Parents engage in a coercive process with the child (Granic \& Patterson, 2006), which the child reciprocates and subsequently uses with teachers and peers. Furthermore, parents can continue to contribute to the child's disruptive behaviors by continuing to engage in these coercive processes during the transition into and through adolescence (Burke, Pardini, \& Loeber, 2008).

In contrast, while the role of parents is acknowledged in the development of anxiety, it is not the central focus of most models. For example, in a model where parents receive more emphasis than in most models, Ginsburg and Schlossberg (2002) include parents in their developmental model of childhood anxiety; however, in contrast to the early starter model for disruptive problems, parenting is not interwoven into the trajectory of the child's anxiety development, which evolves through child centered constructs such as social withdrawal, cognitive distortions, and maladaptive coping strategies. Instead, the parent's own anxiety symptoms, maladaptive coping style, and, finally, anxiety-enhancing parental behaviors are conceptualized as a separate developmental trajectory that impacts the end-result for the child: an anxiety disorder.

\section{Evolution of Behavioral Parenting Interventions with Disruptive Behavior and Anxiety}

In our view, an examination of the evolution of parenting interventions requires consideration of the child's age or developmental level. Interventions for child disruptive behaviors began with young children and focused on behaviors such as oppositionality, noncompliance, and aggression, which often emerge in the preschool years. Because of the developmental level of these children and the questionable impact of "traditional" therapy with the child as the focal client, parents became "co-therapists", implementing behavioral programs in the home. When older children (i.e., 7 years and older) were referred for disruptive behaviors, interventions were no longer restricted to working through parents as many children had the cognitive skills which allowed them to better understand and learn to control their own behavior (e.g., van de Wiel, Matthys, Cohen-Kettenis, Maassen, Lochman, \& van Engeland, 2007; Kazdin, Siegel, \& Bass, 1992; also see Forehand \& Wierson, 1993). As children age into and through adolescence, interventions for disruptive behaviors become more family-focused (e.g., Henggeler \& Schaeffer, 2010), including a focus on communication and problem-solving processes critical to navigating the etiology and maintenance of disruptive behaviors during this developmental period (Forehand \& Wierson, 1993). However, parenting skills in particular continue to be a primary focus of some programs (e.g., Forgatch \& Patterson, 2010) and an important component of most programs.

In contrast to interventions for disruptive behaviors beginning with preschoolers, interventions for child anxiety began with children primarily in the 7- to-14 year old range (e.g., Kendall, 1994). Our view is that this was in large part because of the age at which anxiety was recognized as a legitimate disorder of childhood (see Albano, Chorpita, \& Barlow, 2003). As a function of the age range for which these interventions are targeted, the focus on programs for childhood anxiety has been cognitive behavioral interventions 
conducted directly with the child (e.g., Kendall, Farr, \& Podell, 2010). And, as will be elaborated upon later, the addition of a parenting component for 7 to 14 year old anxious children has not strengthened the outcome beyond cognitive behavioral treatment implemented with the child alone (see Barnish \& Kendall, 2005). However, in recent years, there has been a downward extension of interventions for anxiety disorders to children as young as 2, 3, and 4 years old (Cartwright-Hatton et al., 2011; Hirshfield-Becker et al., 2010; Kennedy et al., 2009; Waters, Ford, Wharton, \& Cogham, 2009). Importantly, relative to the early interventions for anxiety with older children, these downward extensions involve parents in all sessions and rely extensively on parents to implement the intervention.

The treatment of disruptive behaviors and anxiety has had different evolutionary pathways. However, these two pathways appear to be converging: The efficacious treatment of children with disruptive behavior disorders has relied extensively on parent involvement, although the treatment of older children with disruptive behaviors also has included direct work with the child (e.g., van de Wiel et al., 2007). In contrast, treatment of childhood anxiety has been primarily child-focused, although efficacious treatment of younger children with an anxiety disorder is increasingly including a focus on parenting (e.g., CartwrightHatton et al., 2011).

\section{Parental Roles in the Treatment of Disruptive Behavior and Anxiety}

The role of parenting in disruptive problems is well established: Building upon the centrality of parents and the coercive process (Granic \& Patterson, 2006) in the development of disruptive problems, the goal of behavioral parent training is to reduce parent coercive or negative behavior and increase parent positive behavior (e.g., Forgatch \& Patterson, 2010). The outcome of these changes in parenting is a change in the child's disruptive problems (e.g., Chorpita et al., 2011; McMahon et al., 2006).

Relative to parent behavioral training with disruptive behavior problems, parents assume varied roles in the treatment of children's anxiety. As Kendall et al. (2010) highlight, these include "consultants (e.g., provide information), collaborators (e.g., assist with the child's acquisition of coping skills), or co-clients (e.g., learn to manage their own anxiety)" (p. 51). In addition, some programs include a focus on changing parenting behaviors to lead to change in child anxiety (e.g., Rapee, Wignall, Spense, Cobham, \& Lyneham, 2008). The last of these roles is similar to what occurs in behavioral parent training with disruptive behavior; however, in contrast to disruptive behavior, it is only one of multiple roles for parents in most interventions for child anxiety when parents are included. The varied roles of parents in the treatment of child anxiety led Barnish and Kendall (2005) to appropriately conclude: "Given the variability in the content of parent sessions, we recommend prudence when using terms such as ...parent training or parenting sessions” (p. 578).

The varied roles of parents in interventions for anxiety relative to disruptive behavior is likely the result, at least in part, of the evolutionary process delineated earlier. Specifically changing parenting behavior was the core intervention for child disruptive behavior whereas, as we will show later, parenting has been primarily an "add on" to child-directed interventions for anxiety. Not surprisingly, various investigators have targeted different roles parents can play in these "added on" interventions for anxiety.

\section{Specific Parenting Behaviors in the Treatment of Disruptive Behavior and Anxiety}

When parenting behaviors are the target of intervention, are similar parenting behaviors the focus of treatment for child disruptive behaviors and anxiety? The answer is "no". As was 
noted, increasing positive parental behavior and decreasing negative or coercive parental behavior have been the focus of interventions for disruptive problems. Specific targets have included increasing attention for appropriate behavior, exerting more control through setting consistent limits, and ignoring or using time-out for inappropriate behavior (e.g., Forgatch \& Patterson, 2010; McMahon \& Forehand, 2003). For internalizing problems, increasing positive attention for appropriate behavior is emphasized (e.g., Barrett, 1998); however, in contrast to disruptive problems, less control (e.g., being less involved \& directive, granting more autonomy) has been found to be related to lower levels of child anxiety (McLeod, Wood, \& Weisz, 2007) and is emphasized in some treatment programs (e.g., Rapee et al., 2008).

One recent exception to the skills taught to parents in child anxiety treatment programs is noteworthy: Cartwright-Hatton et al. (2011) primarily utilized procedures more typically included in behavioral parent training for disruptive behaviors (e.g., child-directed play, praise, ignoring, time-out) to treat young children's anxiety. As this study was conducted with children with a mean age of 6.5 years, it may be that teaching parents to be more positive and to use appropriate disciplinary procedures, in combination with at least some focus on child-management of anxiety (e.g., managing worry), is sufficient for change of anxiety symptoms in young children. Such an approach also may be sufficient with older children as the non-intervention literature suggests that the parental warmth and hostility are associated with both externalizing and internalizing problems (see McKee et al., 2008, for a review). Alternately, a parent-focused intervention with older children may require targeting parent behaviors specifically associated with child anxiety.

Rakow et al. (2011) have recently emphasized the importance of identifying parenting behaviors more likely to be related to child internalizing symptoms, including anxiety, rather than drawing on models that originated from research on parenting with disruptive behaviors (also see McKee, Colletti, Rakow, Jones, \& Forehand, 2008). The construct of parental psychological control (i.e., controlling a child through guilt, love withdrawal, and other threats or types of manipulation) has been found to relate primarily, or more strongly, to internalizing than externalizing problems (e.g., Barber, Olsen, \& Shagle, 1994; Kincaid, Jones, Cuellar, \& Gonzalez, 2011; Pettit, Laird, Dodge, Bates, \& Criss, 2001). Not surprisingly, this variable has not been included as a target in most parenting interventions for disruptive behaviors. Unfortunately, it also has not been a target of parenting although Settipani, O’Neil, Podell, Beidas, and Kendall (in press) have recently reported changes in parental psychological control and subsequent child anxiety with psychosocial intervention (either child-directed or family-based). This study supports the notion that parental psychological control should be a target of intervention.

\section{Summary Statement: Development, Evolution, and Treatment}

The role of parents in the development, evolution, and treatment of child disruptive behavior and anxiety is substantially different. We have summarized these differences in Figure 1. The arguments we have advanced and the multiple reviews conducted in the literature (e.g., Chorpita et al., 2011; Dretzke et al., 2009) indicate that behavioral parent training is an efficacious intervention with child disruptive behavior problems. However, the state of the field is far less clear with child anxiety. We next attempt to provide some clarity to this issue. It should be noted that in order to do so, we use the term "behavioral parenting interventions;" however, consistent with Barnish and Kendall's (2005) concern about the diversity of procedures which have been grouped under this term, we delineate the specific parenting intervention procedures used in each study. 


\section{What We Know About Behavioral Parenting Interventions with Anxiety}

Although parenting has not historically played as major of a role in the treatment of anxiety, as in the treatment of disruptive behaviors, research in the past 16 years has increasingly examined the role of parenting interventions. Table 1 summarizes these studies. ${ }^{1}$ Four criteria were used for inclusion/exclusion of a study. First, children had to meet diagnostic criteria for a DSM anxiety disorder. Second, as our interest was in clinical samples, examination of change in diagnosis of anxiety from pre-assessment to post-assessment was required. ${ }^{2}$ Third, to qualify as a parenting intervention, more than two sessions had to include parents and parental involvement had to consist of more than receiving information about the child's progress. Fourth, a parent intervention or parent plus child intervention was compared to a child-focused intervention or a control (i.e., wait-list or education/attention/ support) in a group design with random assignment to groups. ${ }^{3}$

Several characteristics of the studies, beyond those summarized in Table 1, are noteworthy. First, the studies were conducted in various countries: Australia $(\mathrm{N}=13)$, the United States $(\mathrm{N}=6)$, the Netherlands $(\mathrm{N}=2)$, and the United Kingdom $(\mathrm{N}=1)$. Second, studies used an individual $(\mathrm{N}=11)$ and group $(\mathrm{N}=9)$ intervention format (two additional studies compared an individual and group format). Third, 19 of 22 studies that had a parent plus child intervention (the remaining three studies had a parent only intervention) in which the parent and child were treated separately $(\mathrm{N}=7)$, together $(\mathrm{N}=4)$, and separately plus together $(\mathrm{N}=$ 8). Thus, as we noted earlier, there is considerable heterogeneity within child anxiety treatment studies that include a parenting component.

Turning to Table 1, the majority of studies included any anxiety disorder whereas a few targeted one or more specific disorders (e.g., OCD, Social Phobia). With four exceptions, studies to date have been conducted with children in the 6 to 18 year age range, with the 7 to 14 year old age range being the most common focus of investigation. The four exceptions, all of which are recent studies, had children in the 3 to 4 age range (Kennedy et al., 2009), 4 to 8 age range (Waters et al., 2009), 4 to 7 age range (Hirshfeld-Becker et al., 2010), and 2 to 9 age range (Cartwright-Hatton et al., 2011). As has been noted, these four studies involved the parent in all sessions and, with the exception of Waters et al., focused primarily on the parent as the agent of change.

Six types of group-design studies with randomization of families, a child anxiety diagnosis, and change in anxiety diagnosis as an outcome have been conducted: (1) Parent intervention versus control; (2) parent plus child intervention versus control; (3) child intervention versus parent plus child intervention; (4) child intervention versus parent plus child intervention versus control; (5) child intervention vs. parent intervention vs. parent plus child intervention; and (6) parent intervention vs. parent plus child intervention vs. control. Of the 18 studies that included a control group, 15 were wait-list and three were labeled as education, attention, and/or support. For the studies that had a wait-list control group, the last assessment occurred at post-intervention [except Cartwright-Hatton et al. (2011) where the wait-list was assessed at 12 months but $38 \%$ of the children had received an intervention] whereas the three education/attention/support groups were assessed during

\footnotetext{
${ }^{1}$ Studies in Table 1 are presented chronologically. Studies reported in Tables 1 and 3 were identified by a search of several databases (e.g., PsycInfo; PubMed) for articles published in peer-reviewed journals. A range of search terms were utilized, individually and in combination. Articles by authors of well-established anxiety (e.g., Barrett, Kendall, Rapee, Silverman) and disruptive behavior (e.g., Eyberg, Kazdin, McMahon, Patterson, Sanders, Webster-Stratton) treatment programs were also examined. Additional articles were found through the examination of the references of those articles found in the initial search.

${ }^{2}$ Two studies (Mendlowitz et al., 1999; Rapee, 2000) were excluded based on this criterion.

${ }^{3}$ Two studies (Manassis et al., 2002; van der Sluis, van der Bruggen, Brechman-Toussaint Thissen \& Bögels, 2012) were excluded because neither a control group nor a comparison child intervention group was included.
} 
follow-up. Across studies in Table 1, parents were involved in 4 to 20 sessions (mean $=10.7$ sessions when booster sessions are included and using a midpoint of number of sessions when there was a range of sessions reported).

As is evident in Table 1, the role of the parent in the intervention varied substantially across studies. Among the major roles were contingency management (e.g., reinforcing nonanxious behavior, ignoring anxious behavior), helping the child with homework (e.g., exposure exercises), and the parent managing her or his own anxiety. This variability begs consideration again of Barnish and Kendall's (2005) conclusion that prudence be used when referring to parenting interventions as parent training in the treatment of children's anxiety. What occurs may have little to do with parent training as conceptualized and traditionally utilized in the treatment of child disruptive behaviors.

The outcomes of various comparisons are reported for each study in Table 1 and are summarized in Table 2. The following conclusions emerge: (1) Parent intervention and parent plus child intervention are more efficacious than a control condition; (2) a parent intervention versus a child intervention has not been examined; and (3) a parent plus child intervention is not more efficacious than parent intervention or, particularly, child intervention. However, there are three caveats to the conclusion regarding parent plus child intervention versus child intervention alone: (a) In two studies (Spence, Donovan, \& Brechman-Toussaint, 2000; Wood, Piacentini, Southam-Gerow, Chu, \& Sigman, 2006), a parent plus child intervention was associated with a better outcome than a child intervention at a "borderline" level of significance $(p<.10)$; (b) when one or both parents have an anxiety disorder, there is some evidence that a parent plus child intervention is more efficacious than a child intervention on at least some outcome measures (Cobham, Dadds, \& Spence, 1998; Kennedy et al., 2009; however, see Bodden et al., 2008, for an exception); and (c) in several studies a child, parent, or clinician report of symptoms (rather than a change in diagnosis of anxiety) indicated a parent plus child intervention was more efficacious than a child intervention (Barnett, 1998; Wood et al., 2006). However, Kendall et al. (2008) found a child intervention was more efficacious than a parent plus child intervention on a teacher report and Bodden et al. (2008) found that a child intervention was more efficacious than a parent plus child intervention at post but not at a 3-month follow-up.

Returning to Table 1 and turning to when data were collected, 20 of 22 studies included follow-ups with 15 of the 20 having a follow-up at 12 months. Longer term follow-up data ( 3 to 13 years) were reported separately for five samples after the original intervention study (see footnotes 1, 2, 3, \& 4 in Table 1). Treatment gains typically were maintained at a 12 month follow-up and subsequently in the studies reporting longer follow-ups. Of importance, with two exceptions, comparisons of two or more types of intervention (parent, child, parent plus child) indicated equivalent efficacy at follow-up. One exception was the Barrett et al. (1996) study where a parent plus child intervention continued from postassessment to the 12-month follow-up to be more efficacious than a child intervention. However, this difference disappeared at a 6-year follow-up (Barrett, Duffy, Dadds, \& Rapee, 2001). The second exception, and one that is particularly noteworthy, is Cobham, Dadds, Spence, and McDermott (2010). In contrast to the finding of no differences between a childdirected cognitive behavioral intervention and a child-directed intervention plus a parenting component (parent management of their own anxiety) at a 12-month follow-up (Cobham et al., 1998), this study found that inclusion of parents led to a better outcome 3 years posttreatment. Thus, inclusion of parents in the intervention may not enhance treatment outcome within the first year but may lead to better longer-term outcome for children. This conclusion has intuitive and logical appeal: If parents are engaged in the treatment process, they will be more likely to manage their own anxiety and/or promote maintenance of child behavior change long after treatment terminates. 
Of particular importance for our purposes, only one study included a measure of parenting (see Table 1): Silverman et al. (2009) used a youth report measure of parenting. This stands in marked contrast to studies with disruptive problems where change in parenting behaviors pre- to post- treatment and at follow-up are assessed as standard protocol, which is consistent with the conceptualization of parenting as the agent of change in child behavior. As an example, of the 34 studies of interventions for child disruptive behavior reviewed by Eyberg et al. (2008), 21 studies had a parenting component and of these $15(76 \%)$ assessed and reported parenting. Of these 15 studies, $12(80 \%)$ reported observational data, arguably the most objective, rigorous, and time-consuming type of data to collect.

Finally, it is important to note that for the groups labeled as "child intervention," parents were involved at least minimally. For example, in Coping Cat, the therapist meets with the parents in two of 16 sessions to explain the treatment to the parents, update parents on progress, discuss parental concerns, and prepare parents for increased anxiety as the child begins exposure treatment (Kendall et al., 2010).

\section{Summary}

Research examining the role of parents as intervention agents for children's anxiety has only emerged in the last 16 years. From this work, four conclusions are evident. First, inclusion of parents (either alone or in combination with a child intervention) is efficacious relative to a control condition for treatment of anxiety. Second, with the exception of the earliest study (Barrett et al., 1996) and one long-term follow-up (Cobham et al., 2010), inclusion of parents in combination with a child intervention is no more efficacious than only a childdirected intervention. Third, a parenting intervention alone has not been contrasted to a child intervention alone. Forth, studies have failed to report on measures of parenting behavior or change in parenting behavior as a function of the intervention; as a consequence, it is not possible to determine if parenting behaviors changed with intervention, and more importantly, the extent to which remission of child anxiety is a function of change in parent behavior. We now turn our attention to the literature which does examine parenting as the mechanism of change.

\section{Is Parenting the Mechanism of Change in Behavioral Parenting Interventions?}

The focus on parents in an intervention does not necessarily mean that the parenting behaviors targeted account for change that occurs in child behavior. Change in parenting must be shown to result from the intervention and then this change must lead to change in child outcome (see Kendall et al., 2012). Although change in parenting behavior is the assumed mechanism by which behavioral parent training leads to improvement in child behavior, only nine studies explicitly examined parenting behaviors as a mediator of change in child disruptive behavior (see Table 3). Of these nine studies, only three (Beauchaine, Webster-Stratton, \& Reid, 2005; Fossum et al., 2009; Webster-Stratton \& Herman, 2008) used DSM diagnostic criteria (ODD or CD) for study entry. Five of the nine studies examined Webster-Stratton's Incredible Years (IY), one examined Multi-Systemic Therapy (MST), and three examined the Parent Management Training - Oregon (PMTO) model or a derivative of PMTO (Multi-dimensional Treatment Foster Care - MTFC).

The IY studies were conducted with children from 2 to 9 years of age and each found some support for either positive parenting or negative parenting serving as a mediator. However, consistent support across studies did not emerge for either construct (e.g., support for positive parenting was found in two of four studies). The two PMTO studies were with the same sample of 4 to 12 year old children and both found support for parental discipline as a 
mediator, one at post-assessment and one at follow-up (see footnote 1 in Table 3). The derivative MTFC study, implemented with 12 to 17 year old youth, found support for mediation with a construct that included three positive parenting behaviors and a youth construct (association with deviant peers). The MST study, conducted with 11 to 18 year olds, found that discipline was a mediator.

In summary, support does exist for parenting as a mediator of disruptive problems; however, the small number of studies, the intervention program utilized, age of child, and findings (e.g., positive versus negative parenting) make it difficult to reach more general conclusions. Furthermore, if the same criteria utilized for inclusion of interventions for child anxiety in Table 1 were employed (e.g., diagnosis of ODD or CD for inclusion), then the number of studies identified shrink considerably. Finally, temporal precedence (i.e., assessment of change in the mediator before assessment of change in the outcome variable) is a requirement of establishing mediation (see Kendall et al., 2012) and multiple studies in Table 3 failed to meet this criterion (e.g., Fossum et al., 2009; Ogden \& Hagen, 2008).

The state-of-the-field regarding mediators of change in child disruptive behaviors with a parenting intervention is somewhat surprising, especially considering the number of studies which have examined parenting as an intervention for these types of behaviors (see Chorpita et al., 2011). Furthermore, as our example from the Eyberg et al. (2008) review indicated, a great majority of studies have assessed and reported parenting behaviors. Clearly, researchers need to move beyond the assessment of change in parenting behaviors with intervention to testing whether these behaviors are mediators of change in parenting programs for child disruptive behaviors. ${ }^{4}$

Not surprisingly as only one study has reported parenting behaviors when treating child anxiety (Silverman et al., 2009), parenting has rarely been examined as a mediator of change in this literature. However, the Silverman et al. (2009) study did examine mediation by conducting two lagged effects analyses after a family intervention for child anxiety was implemented in order to address the following questions: (a) are reductions in positive/ negative parenting associated with subsequent reductions in child anxiety symptoms; and (b) are reductions in child anxiety symptoms associated with subsequent reductions in positive/ negative parenting? They found support for the latter, but not former, relationship, suggesting that changes in parenting did not account for changes in child anxiety symptoms.

Three additional studies deserve mention. First, Webster-Stratton and Herman (2008) examined not only child disruptive problems but also internalizing problems (which includes anxiety) as an outcome when children were referred for ODD or CD. Parent reported parenting efficaciousness (i.e., perceived success as a parent, perceived emotional closeness to child, did not view parenting responsibilities as frustrating) was a mediator of the parent behavioral training treatment effects on child internalizing problems. Although the parenting efficaciousness measure utilized did not assess parenting behaviors per se (but rather how efficacious parents perceived themselves to be) and child anxiety specifically was not assessed, this study moves the field in the right direction by including a proxy for parenting and the assessment of both externalizing and internalizing problems. Second, Khanna and Kendall (2009) did not examine parenting behaviors but did examine the quantity and quality of the therapist teaching specific parenting skills and whether these measures predicted child outcome. Higher ratings of teaching parent anxiety management and transfer of control to the child (but not communication skills or contingent management) predicted parent-reported and clinician-reported, but not child-reported, outcomes. This study began to

\footnotetext{
${ }^{4}$ Numerous prevention studies not reviewed here have found support for parenting as a mediator (e.g., Forgatch, Patterson, DeGarmo, \& Beldavs, 2009).
} 
explore the role of therapist-administered parenting training but did not examine actual parent behaviors and did not conduct mediational analyses. Third, a recent study by Settipani et al. (in press) combined the two intervention groups (i.e., child intervention and parent plus child intervention) reported in Kendall et al. (2008) and examined post-treatment to follow-up change in parental psychological control (e.g., guilt induction, love withdrawal) and child anxiety. Cross-lagged comparisons indicated that decreases in psychological control predicted decreases in youth anxiety but youth anxiety did not predict psychological control. As the authors note, this finding provides support for a parenting influence on child anxiety.

In summary, the Silverman et al. (2009) study does not provide support for parenting as a mediator in the treatment of child anxiety. However, although not directly examining mediation, three additional studies to date begin to explore the role of parenting in the treatment of child anxiety. Accordingly, future research examining the potential pathways and mechanisms by which parent involvement in treatment impacts anxiety is critical to the advancement of this literature.

\section{Directions for Future Research: Disruptive Behaviors}

\section{Testing Specific Parenting Behaviors Targeted in Interventions}

Although some basic research has examined the extent to which specific parenting behaviors (e.g., praise) are associated with specific child outcomes (e.g., noncompliance), far less applied research has been devoted to the issue of specificity (e.g., Jones, Forehand, Rakow, McKee, Colletti, \& Zalot, 2008; also see McKee et al., 2008, for a review). Instead, as noted in Table 3, parenting behaviors often have been collapsed into broader categories, such as positive parenting and efficacious discipline. In order to better identify the specific agents of change in parent training, specific parenting behaviors targeted within an intervention (e.g., praising appropriate behavior, ignoring minor inappropriate behavior, limit setting) need to be assessed and examined as mediators of change.

\section{Expanding the Role of Parents in Interventions}

zThe treatment of child disruptive problems could use the varied roles that parents have played in the treatment of anxiety as a model for expansion. Parents could be involved not only in the change of their own parenting behaviors (e.g., positive reinforcement, ignoring, time-out) but as consultants (provide information), collaborators (help child acquire new skills), and co-clients (manage their own mental health problems). In reality, many parenting programs already do involve parents in these roles, but in an informal way. For example, parents provide information about their child's behavior by tracking the behaviors (e.g., McMahon \& Forehand, 2003; Forgatch \& Patterson, 2010), help even young children acquire new skills (e.g., posting and daily review of rules to facilitate learning) (e.g., Forehand \& Long, 2010; McMahon \& Forehand, 2003), and, when they interfere with treatment, manage their own mental health problems (see Forehand \& Long, 2010; McMahon \& Forehand, 2003). However, there is certainly room to include parents in even more systematic and meaningful ways in these and other capacities.

\section{Are Parenting Interventions Necessary or Sufficient?}

The literature regarding parenting programs for child disruptive problems provides evidence that parenting programs are sufficient for child behavior change. However, an equally important question, and one that has received some attention in the child anxiety treatment literature (see Table 2), is whether parenting interventions are necessary. Can a childdirected intervention achieve equally efficacious results as a parent-directed intervention? This is an important question because some parents believe their child, not their own 
parenting skills, should be the focus of therapy. Other parents have stressors, whether personal (e.g., their own mental health problems), familial (e.g., interparental conflict), or extrafamilial (e.g., living in a high risk neighborhood), which interfere with being the agent of change in therapy. As a consequence, parental engagement in parenting programs can be problematic in some families (see Ingoldsby, 2010, for a review).

If interventions can be child-directed, then for some families child behavior can change regardless of parent engagement in intervention. Some evidence suggests that a childdirected intervention for children 7 years and older can be at least as efficacious as a parentdirected intervention (e.g., Kazdin et al., 1992). Even with younger children, WebsterStratton and Hammond (1997) found support for this conclusion; however, parents and teachers were involved in the child-directed treatment in that they were updated weekly, reinforced targeted behaviors, and utilized good behavior charts. Thus, similar to recent interventions with anxiety problems, particularly when children are preschool age (e.g., Hirshfeld-Becker et al., 2010), some parent involvement appears to be an inherent part of child-directed treatment. This conclusion is not inconsistent with interventions with older children: Kazdin et al.'s (1992) child-directed treatment had parents learning and prompting the child's use of problem solving.

An additional finding from the Kazdin et al. (1992) and Webster-Stratton and Hammond (1997) research is that a parent plus child intervention is more efficacious than a parenting intervention or child intervention alone. This conclusion, which we would view as tentative at this time, is different than the one that emerged in the anxiety literature: Two of the three studies found that a parent plus child intervention was not more efficacious than a parent only intervention (see Table 2). Future research with disruptive behaviors needs to address not only if a parenting component is necessary but if a parent plus child treatment is more efficacious.

\section{Direction for Future Research: Anxiety Measure Parenting Behaviors}

With only one study of anxiety treatment assessing parenting behaviors, it is apparent that these behaviors need to be measured before conclusions about parenting interventions can be reached. As Wood et al. (2006) appropriately concluded: "The next step will be to see whether FCBT (family cognitive behavioral therapy) changed parenting practices as expected and to test for a mediating role of parenting practices in the reduction of youth anxiety" (p. 320) (also see Kendall et al., 2012). Such work will inform the identification of the clinical mechanisms leading to improvement in child anxiety.

\section{Compare Different Roles of Parenting}

As we have noted several times, parents have played various roles in interventions for child anxiety problems: Consultant, collaborator, co-client, and the traditional agent of change of child behavior. Each of these roles appears to be important, but some may be more critical than others. Furthermore, some combinations of these roles may enhance treatment outcome for children relative to casting parents into one role in an intervention. At this point research has not yet begun to address these questions.

\section{Develop Behavioral Parenting Programs Based on the Non-Intervention Literature}

McLeod and his colleagues (2007) conducted a thorough review of the literature examining the associations of parenting behaviors with child anxiety. Autonomy-granting emerged as a particularly important parenting behavior. Although the amount of variance accounted for by parenting may be small thus far (see McLeod et al., 2007), research continues to identify 
specific parenting behaviors which can be used to build and test interventions to help parents alleviate their child's symptoms of anxiety (for recent examples, see Schwartz, Dudgeon, Sheeber, Yap, Simmons, \& Allen, 2012; Williams, Kertz, Schrock, \& Woodruff-Borden, 2012). And, if these parenting interventions can improve child anxiety beyond those achieved by child-focused interventions alone, then changing these parental behaviors becomes particularly meaningful.

\section{Overarching Directions for Future Research: Disruptive Behavior and Anxiety}

\section{Collect Long Term Follow-up Data}

Intuitively, as we have noted, inclusion of a parenting component should help promote longterm gains in the treatment of child problems. As examples, parents could use their therapeutically acquired parenting skills to address new, or relapses in, child disruptive or anxious behaviors or could coach a child to apply skills they learned in therapy to new problems or ones where relapse has occurred. In contrast to post-treatment and shorter term follow-up data (see Table 1), Cobham et al's (2010) 3-year follow-up data suggest this could be the case for child anxiety. Long-term outcome data from studies with disruptive behaviors and anxiety which compare an intervention with a parenting component to one that is child-directed are needed.

\section{Examine Moderators of Treatment Response}

Treatments do not work the same for all families and under all conditions. Behavioral parent training is no exception. Multiple moderators of behavioral parent training for child disruptive behaviors have been identified. For example, single parent families and socioeconomically disadvantaged families tend to benefit less from behavioral parent training for disruptive behaviors, while girls and children with more severe behavior problems at baseline may benefit more (e.g., Lavigne et al., 2008; also see Lundahl, Risser, $\&$ Lovejoy, 2006, for a review). Some work has begun to examine potentially important moderators (e.g., parental anxiety) in parenting interventions for child anxiety disorders as well (e.g., Kendall et al., 2008). Furthermore, Breinholst et al. (2012) recently published a thoughtful discussion on why parental involvement, which itself can be considered a moderator, in the treatment of child anxiety has not enhanced outcomes. Of importance, the inclusion of larger sample sizes in future work will be critical to facilitate examination of other treatment moderators (e.g., child gender \& age) to identify for whom and under what conditions behavioral parenting interventions for disruptive behavior disorders and childhood anxiety do or do not work.

Before turning from a consideration of moderators, the role of ethnicity and race deserve mention. In a recent review, Huey and Polo (2008) identified a number of evidence-based treatments that have been successful in predominantly ethnic minority youth samples. Of note, only a few of those reviewed involved parents in the treatment of anxiety (see Silverman et al., 2009, as an exception) or disruptive behaviors (e.g., see Lochman \& Wells, 2004, as an exception). As highlighted by Lau (2006), the relative dearth of research on racial and ethnic minority children and families makes it difficult to determine the extent to which interventions should work similarly for these underserved groups or, alternatively, whether cultural adaptations would be necessary to ensure engagement and treatment efficacy. More research is necessary to determine whether race, ethnicity, or other sociocultural variables, including income, may shape not only parenting behavior, but the impact of parenting behavior on children's symptomatology and, in turn, the potential role and impact of parents in treatment process. As a potential first step, more research is needed 
with samples of ethnic minority youth or samples that are sufficiently large and diverse enough to examine these variables as moderators.

\section{Treatment of Disruptive Behavior and Anxiety}

Although comorbidity of child disruptive behaviors and anxiety is well acknowledged in the literature (e.g., Drabick, Ollendick, \& Bubier, 2010; Nock, Kazdin, Hiripi, \& Keller, 2007), controlled studies of parenting interventions for dual diagnoses across these two broadband types of problems are, to the best of our knowledge, non-existent (see Ale \& Krackow, 2011, for a case study and Chase \& Eyberg, 2008, for an uncontrolled study). Considering the current state of the separate bodies of treatment outcome research for disruptive behaviors and anxiety presented here, this is perhaps not surprising; nevertheless, these separately evolving literatures tell us little about the type and level of parental involvement that is ideal for children with comorbid diagnoses. Furthermore, once such interventions are developed, it will be important to examine if change in specific parenting behaviors (e.g., praise, behavioral control) is the mechanism that accounts for change in both child disruptive behavior and anxiety. One behavior, parental control, in particular needs attention: As we noted earlier, more control has been associated with improvements in disruptive behavior and less control has been associated with improvements in anxiety.

The Modular Approach to Therapy for Children with Anxiety, Depression, Trauma, or Conduct Problems (MATCH-ADTC) program, and recently demonstrated by Weisz et al. (2012) to be more effective than standard manualized treatment, developed by Chorpita and Weisz (2009) provides an excellent example of an intervention approach that considers and addresses, if necessary, the multiple disorders with which a child may present. MATCHADTC is a modular treatment based on empirically supported interventions for anxiety, depression, trauma, and conduct problems. A child is matched to an intervention based on her or his presenting symptoms (see Eisen \& Silverman, 1998, and Kearney \& Silverman, 1999 , for two early examples of matching treatment to symptoms with anxious children). Of particular importance for our consideration in the MATCH-ADTC program, a child can be switched to a different module if warranted. Not surprisingly, based on the literature reviewed in this paper, only the intervention for conduct problems has a focus on parents. In the future there may well be sufficient evidence to warrant an intervention that has a parenting focus for both child disruptive behavior (conduct problems) and anxiety, particularly for younger children and in cases for which the presenting issues are linked, at least in part, to specific parenting behaviors (i.e., coercive cycle for disruptive behaviors and over-controlled parenting for anxiety). Certainly, the literature on treatment of child anxiety we have reviewed suggests that inclusion of parents in the intervention is as efficacious (but not more so) as a child-directed intervention.

Of importance, treatment selection needs to go beyond the set of symptoms with which a child presents to the case conceptualization for why the symptoms developed and are being maintained. For example, child anxiety occurring in the context of over-controlling parenting would be more likely to warrant inclusion of parents in an intervention than anxiety conceptualized to stem from factors specific to the child (e.g., cognitive processes) or external to the family (e.g., peers). This functional approach to the treatment of both child disruptive behaviors and anxiety has long been recognized (see Dangle \& Polster, 1984; Scotti, Morris, McNeil, \& Hawkins, 1996) and deserves renewed attention.

\section{Conclusions}

In his 1962 case study, Boardman reached the following conclusion regarding an intervention that resembles what today is called behavioral parent training for disruptive behavior problems: 
"A procedure such as this produces rapid results - or none at all. In properly selected cases the probability of success is high, and the major risk involved lies in the assumption that the parent or parents are capable of initiative, rapid learning, and insight when faced with the responsibility for all of the actions required for repairing the relationship with their child. Many parents deserve such a vote of confidence" (p. 297).

The field of behavioral parenting interventions obviously has come a long way in the past 50 years. However, as is evident from the literature reviewed in this paper and particularly the directions for future research, there is still important work to be done. And, as Boardman notes, parents do deserve a vote of confidence by being "a co-therapist" for their child when the literature supports their inclusion in the therapeutic process!

\section{Acknowledgments}

The support of the Heinz and Rowena Ansbacher Professorship and the National Institute of Mental Health (R34MH082956; Clinical Trials Identifier: NCT01367847) is gratefully acknowledged. In addition, the insightful comments of two anonymous reviewers are acknowledged.

\section{References}

Albano, AM.; Chorpita, BF.; Barlow, DH. Child anxiety disorders. In: Mash, EJ.; Barkley, RA., editors. Child psychopathology. New York: Guilford; 2003. p. 273-329.

Ale CM, Krackow E. Concurrent treatment of early childhood OCD and ODD: A case illustration. Clinical Case Studies. 2011; 10:312-323.

American Psychiatric Association. Diagnostic and statistical manual of mental disorders (4th ed., text rev.). Washington, DC: Author; 2000.

Barber, BK.; Harmon, EL. Violating the self: Parental psychological control of children and adolescents. In: Barber, BK., editor. Intrusive parenting. How psychological control affects children and adolescents. Washington, DC: American Psychological Association; 2002. p. 15-52.

Barber BK, Olsen JA, Shagle S. Associations between parental psychological control and behavioral control and youth internalized and externalized behaviors. Child Development. 1994; 65:1120 1136. [PubMed: 7956469]

Barrett PM. Evaluation of cognitive-behavioral group treatments for childhood anxiety disorders. Journal of Clinical Child Psychology. 1998; 27:459-468. [PubMed: 9866083]

Barrett PM, Dadds MR, Rapee RM. Family treatment of childhood anxiety: A controlled trial. Journal of Consulting and Clinical Psychology. 1996; 64:333-342. [PubMed: 8871418]

Barrett PM, Duffy AL, Dadds MR, Rapee RM. Cognitive-behavioral treatment of anxiety disorders in children: Long-term (6-year) follow-up. Journal of Consulting and Clinical Psychology. 2001; 69:135-141. [PubMed: 11302272]

Barrett P, Farrell L, Dadds M, Boulter N. Cognitive-behavioral family treatment of childhood obsessive-compulsive disorder: Long-term follow-up and predictors of outcome. Journal of the American Academy of Child and Adolescent Psychiatry. 2005; 44:1005-1014. [PubMed: 16175105]

Barrett P, Healy-Farrell L, March JS. Cognitive-behavioral family treatment of childhood obsessivecompulsive disorder: A controlled trial. Journal of the American Academy of Child and Adolescent Psychiatry. 2004; 43:46-62. [PubMed: 14691360]

Barnish AJ, Kendall PC. Should parents be co-clients in cognitive behavioral therapy for anxious youth? Journal of Clinical Child and Adolescent Psychology. 2005; 34:569-581. [PubMed: 16026220]

Beauchaine TP, Webster-Stratton C, Reid MJ. Mediators, moderators, and predictors of 1-year outcomes among children treated for early-onset conduct problems: A latent growth curve analysis. Journal of Consulting and Clinical Psychology. 2005; 73:371-388. [PubMed: 15982136]

Bernal ME, Duryee JS, Pruett HL, Burns BJ. Behavior modification and the brat syndrome. Journal of Consulting and Clinical Psychology. 1968; 32:447-455. [PubMed: 5666146] 
Boardman WK. Rusty: A brief behavior disorder. Journal of Consulting Psychology. 1962; 26:293297. [PubMed: 13870275]

Bodden DHM, Bogels SM, Nauta MH, Haan ED, Ringrose J, Appelboom C, Appelboom-Geerts MS. Child versus family cognitive behavioral therapy in clinically anxious youth: An efficacy and partial effectiveness study. Journal of American Academy of Child \& Adolescent Psychiatry. 47:1384-1394.

Breinholst S, Esbjorn BH, Reinholdt-Dunne ML, Stallard P. CBT for the treatment of child anxiety disorders: A review of why parental involvement has not enhanced outcomes. Journal of Anxiety Disorders. 2012; 26:416-424. [PubMed: 22306129]

Burke JD, Pardini DA, Loeber R. Reciprocal relationships between parenting behavior and disruptive psychopathology from childhood through adolescence. Journal of Abnormal Child Psychology. 2008; 36:679-692. [PubMed: 18286366]

Cartwright-Hatton S, McNally D, Field AP, Rust S, Laskey B, Woodham A. A new parenting-based group intervention for young anxious children: Results of a randomized controlled trial. Journal of the American Academy of Child and Adolescent Psychiatry. 2011; 50:242-251. [PubMed: 21334564]

Chase RM, Eyberg SM. Clinical presentation and treatment outcome for children with comorbid externalizing and internalizing. Journal of Anxiety Disorders. 2008; 22:273-282. [PubMed: 17467229]

Chorpita BF, Daleiden EL, Ebesutani C, Young J, Becker KD, Starace N. Evidence-based treatments for children and adolescents: An updated review of indicators of efficacy and effectiveness. Clinical Psychology: Science and Practice. 2011; 18:154-172.

Chorpita, BF.; Weisz, JR. MATCH-ADTC. Satellite Beach, FL: PracticeWise; 2009.

Cobham VE, Dadds MR, Spence SH. The role of parental anxiety in the treatment of childhood anxiety. Journal of Consulting and Clinical Psychology. 1998; 66:893-905. [PubMed: 9874902]

Cobham VE, Dadds MR, Spence SH, McDermott B. Parental anxiety in the treatment of childhood anxiety: A different story three years later. Journal of Clinical Child and Adolescent Psychology. 2010; 39:410-420. [PubMed: 20419581]

Dadds MR, Heard PM, Rapee RM. The role of family intervention in the treatment of child anxiety disorders: Some preliminary findings. Behavior Change. 1992; 9:171-177.

Dangle, RF.; Polster, RA., editors. Parent training. New York: Guilford Press; 1984.

Dodge KA, Greenberg MT, Malone PS. Testing an idealized cascade model of the development of serious violence in adolescence. Child Development. 2009; 74:1907-1925.

Drabick DAG, Ollendick TH, Bubier JL. Co-occurrence of ODD and anxiety: Shared risk processes and evidence for a dual-pathway model. Clinical Psychology: Science and Practice. 2010; 17:307318. [PubMed: 21442035]

Dretzke J, Davenport C, Frew E, Barlow J, Stewart-Brown S, Hyde C. The clinical effectiveness of different parenting programmes for children with conduct problems: A systematic review of randomized controlled trials. Child and Adolescent Psychiatry and Mental Health. 2009; 3:7. [PubMed: 19261188]

Eddy JM, Chamberlain P. Family management and deviant peer association as mediators of the impact of treatment condition on youth antisocial behavior. Journal of Consulting and Clinical Psychology. 2000; 68:857-863. [PubMed: 11068971]

Eisen AR, Silverman WK. Prescriptive treatment for generalized anxiety disorder in children. Behavior Therapy. 1998; 29:105-121.

Eyberg SM, Nelson MM, Boggs SR. Evidence-based psychosocial treatments for children and adolescents with disruptive behavior. Journal of Clinical Child and Adolescent Psychology. 2008; 37:215-237. [PubMed: 18444059]

Flannery-Schroeder EC, Kendall PC. Group and individual cognitive-behavioral treatments for youth with anxiety disorders. A randomized clinical trial. Cognitive Therapy and Research. 2000; 24:251-278.

Forehand, R.; Long, N. Parenting the strong-willed child. 3. New York: McGraw-Hill; 2010.

Forehand R, Wierson M. The role of developmental factors in planning behavioral interventions: Disruptive behavior as an example. Behavior Therapy. 1993; 22:671-688. 
Forgatch, MS.; Patterson, GR. Parent management training - Oregon model: An intervention for antisocial behaviors in children and adolescents. In: Weisz, JR.; Kazdin, AE., editors. Evidencedbased psychotherapies for children and adolescents. 2. New York: Guilford; 2010. p. 159-178.

Forgatch MS, Patterson GR, DeGarmo DS, Beldavs ZG. Testing the Oregon delinquency model with 9-year follow-up of the Oregon Divorce Study. Development and Psychopathology. 2009; 21:637660. [PubMed: 19338702]

Fossum S, Morch WT, Handegard BH, Drugle MB, Larsson B. Parent training for young Norwegian children with ODD and CD problems: Predictors and mediators of treatment outcome. Scandinavian Journal of Psychology. 2009; 50:173-181. [PubMed: 19170971]

Gardner F, Burton J, Klimes I. Randomized controlled trial of a parenting intervention in the voluntary sector for reducing child conduct problems: Outcomes and mechanisms of change. Journal of Child Psychology and Psychiatry. 2006; 47:1123-11132. [PubMed: 17076751]

Gardner F, Hutchings J, Bywater T, Whitaker C. Who benefits and how does it work? Moderators and mediators of outcome in an effectiveness trial of a parenting intervention. Journal of Clinical Child and Adolescent Psychology. 2010; 39:568-580. [PubMed: 20589567]

Ginsburg GS, Schlossberg MC. Family-based treatment of childhood anxiety disorders. International Review of Psychiatry. 2002; 14:143-154.

Ginsburg GS, Silverman WK, Kurtines WK. Family involvement in treating children with phobic and anxiety disorders: A look ahead. Clinical Psychology Review. 1995; 15:457-473.

Granic I, Patterson GR. Toward a comprehensive model of antisocial development: A dynamic systems approach. Psychological Review. 2006; 113:101-131. [PubMed: 16478303]

Gureasko-Moore D, DuPaul GJ, Power TJ. Stimulant treatment for attention-Deficit/Hyperactivity disorder: Medication monitoring practices of school psychologists. School Psychology Review. 2005; 34:232-245.

Hagen KA, Ogden T, Bjornebekk G. Treatment outcomes and mediators of parent management training: A one-year follow-up of children with conduct problems. Journal of Clinical Child and Adolescent Psychology. 2011; 40:165-178. [PubMed: 21391015]

Hanf, C. A two-stage program for modifying maternal controlling during mother-child (M-C) interaction. Paper presented at the meeting of the Western Psychological Association; Vancouver, BC, Canada. 1969.

Henggeler, SW.; Schaeffer, C. Treating serious antisocial behavior using multisystemic therapy. In: Weisz, JR.; Kazdin, AE., editors. Evidence-based psychotherapies for children and adolescents. 2. New York: Guilford; 2010. p. 259-276.

Henggeler SW, Letourneau EJ, Chapman JE, Bourduin CM, McCart MR. Mediators of change for multisystemic therapy with juvenile sexual offenders. Journal of Consulting and Clinical Psychology. 2009; 77:451-462. [PubMed: 19485587]

Hindshaw, SP.; Lee, SS. Conduct and oppositional defiant disorder. In: Mash, EJ.; Barkley, A., editors. Child psychopathology ( $2^{\text {nd }}$ ed.). New York: Guilford Press; 2003. p. 144-198.

Hirshfeld-Becker DR, Masek B, Henin A, Blakely LR, Pollock-Wurman RA, McQuade J, Biederman J. Cognitive behavioral therapy for 4- to 7- year-old children with anxiety disorders: A randomized clinical trial. Journal of Consulting and Clinical Psychology. 2010; 78:498-510. [PubMed: 20658807]

Holmbeck, GN.; Devine, KA.; Bruno, EF. Developmental issues and considerations in research and practice. In: Weisz, JR.; Kazdin, AE., editors. Evidence-based psychotherapies for children and adolescents. 2. New York: Guilford; 2010. p. 28-39.

Howard BL, Kendall PE. Cognitive-behavioral family therapy for anxiety-disordered children: A multiple-baseline evaluation. Cognitive Therapy and Research. 1996; 20:423-443.

Ingoldsby EM. Review of interventions to improve family engagement and retention in parent and child mental health programs. Journal of Child and Family Studies. 2010; 19:629-645. [PubMed: 20823946]

Jones DJ, Forehand R, Rakow A, Colletti C, McKee L, Zalot A. The specificity of maternal parenting behavior and child adjustment difficulties: A study of inner-city African American families. Journal of Family Psychology. 2008; 22:181-192. [PubMed: 18410205] 
Hudson JL, Rapee RM, Deveney C, Schniering CA, Lyneham HJ, Bovopoulos N. Cogntive-behavioral treatment versus an active control for children and adolescents with anxiety disorders: A randomized trial. Journal of the American Academy of Child and Adolescent Psychiatry. 2009; 48:533-544. [PubMed: 19318990]

Huey SJ Jr, Polo AJ. Evidence-based psychosocial treatments for ethnic minority youth. Journal of Clinical Child \& Adolescent Psychology. 2008; 37:262-301. [PubMed: 18444061]

Kazdin AE, Siegel TC, Bass D. Cognitive problem-solving skills training and parent management training in the treatment of antisocial behavior in children. Journal of Consulting and Clinical Psychology. 1992; 60:733-747. [PubMed: 1401389]

Kearney CA, Silverman WK. Functionally based prescriptive and nonprescriptive treatment for children and adolescents with school refusal behavior. Behavior Therapy. 1999; 30:673-695.

Kendall PC. Treating a disorder in children: Results of a randomized clinical trial. Journal of Consulting and Clinical Psychology. 1994; 62:100-110. [PubMed: 8034812]

Kendall, PE.; Furr, JM.; Podell, JL. Child-focused treatment of anxiety. In: Weisz, JR.; Kazdin, AE., editors. Evidenced-based psychotherapies for children and adolescents. 2. New York: Guilford; 2010. p. 45-60.

Kendall PE, Howard BL, Epps J. The anxious child: Cognitive-behavioral treatment strategies. Behavior Modification. 1988; 12:281-310. [PubMed: 3069097]

Kendall PE, Hudson JL, Gosch E, Flannery-Schroeder E, Suveg C. Cognitive-behavioral therapy for anxiety disordered youth: A randomized clinical trial evaluating child and family modalities. Journal of Consulting and Clinical Psychology. 2008; 76:282-297. [PubMed: 18377124]

Kendall PC, Southam-Gerow MA. Long-term follow-up of a cognitive-behavioral therapy for anxietydisorderd youth. Journal of Consulting and Clinical Psychology. 1996; 64:724-730. [PubMed: 8803362]

Kendall PC, Settipani CA, Cummings CM. No need to worry: The promising future of child anxiety research. Journal of Clinical Child and Adolescent Psychology. 2012; 41:103-115. [PubMed: 22233250]

Kennedy SJ, Rapee RM, Edwards SL. A selective intervention program for inhibited preschool-aged children of parents with an anxiety disorders: Effects on current anxiety disorders and temperament. Journal of the American Academy of Child and Adolescent Psychiatry. 2009; 48:602-609. [PubMed: 19454916]

Khanna MS, Kendall PD. Exploring the role of parent training in the treatment of child anxiety. Journal of Consulting and Clinical Psychology. 2009; 77:981-986. [PubMed: 19803577]

Kincaid C, Jones DJ, Cuellar J, Gonzalez M. Psychological control associated with youth adjustment and risky behavior in African American single mother families. Journal of Child and Family Studies. 2011; 20:102-110.

Lavigne J, LeBailly S, Gouze KR, Cicchetti C, Jessup BW, Arend R, Binns H. Predictor and moderator effects in the treatment of oppositional defiant disorder in pediatric primary care. Journal of Pediatric Psychology. 2008; 33:462-472. [PubMed: 17956931]

Lau AS. Making the case for selective and directed cultural adaptations of evidence- based treatments: Examples from parent training. Clinical Psychology: Science \& Practice. 2006; 13:295-310.

Lochman JE, Wells KC. The Coping Power Program for preadolescent aggressive boys and their parents: Outcome effects at the 1-year follow-up. Journal of Consulting and Clinical Psychology. 2004; 72:571-578. [PubMed: 15301641]

Lundahl B, Risser HJ, Lovejoy MC. A meta-analysis of parent training: Moderators and follow-up effects. Clinical Psychology Review. 2006; 26:86-104. [PubMed: 16280191]

Lyneham HJ, Rapee RM. Evaluation of therapist-supported parent-implemented CBT for anxiety disorders in rural children. Behaviour Research and Therapy. 2006; 44:1287-1300. [PubMed: 16313883]

Manassis K, Mendlowitz SL, Scapillato D, Owens M. Group and individualcognitive-behavioral therapy for childhood anxiety disorders: A randomized trial. Journal of the American Academy of Child and Adolescent Psychiatry. 2002; 41:1423-1430. [PubMed: 12447028] 
Maughan DR, Christiansen E, Jenson WR, Olympia D, Clark E. Behavioral parent training as a treatment for externalizing behaviors and disruptive behavior disorders: A meta-analysis. School Psychology Review. 2005; 34:267-286.

McKee L, Colletti C, Rakow A, Jones DJ, Forehand R. Parenting and child externalizing behaviors: Are the associations specific or diffuse? Aggression and Violent Behaviors. 2008; 13:201-215.

McLeod BD, Wood JJ, Weisz JR. Examining the association between parenting and childhood anxiety: A meta-analysis. Clinical Psychology Review. 2007; 27:986-1003. [PubMed: 17449154]

McMahon, RJ.; Forehand, R. Helping the noncompliant child. (2nd ed.). New York: Guilford; 2003.

McMahon, RJ.; Wells, KC.; Kotler, JS. Conduct problems. In: Mash, EJ.; Barkley, RA., editors. Treatment of childhood disorders. 3. New York: Guilford Press; 2006. p. 137-268.

Mendlowitz SL, Manassis K, Bradley S, Scapillato D, Miezities S, Shaw BF. Cognitive-behavioral group treatments in childhood anxiety disorders: The role of parental involvement. Journal of American Academy of Child and Adolescent Psychiatry. 1999; 38:1223-1229.

Moffitt TE, Arseneault L, Jaffee SR, Kim-Cohen J, Koenen KC, Viding E. Research review: DSM-V conduct disorder: research needs for an evidence base. Journal of Child Psychology and Psychiatry. 2008; 49:3-33. [PubMed: 18181878]

Nauta MH, Scholing A, Emmelkamp PMG, Minderaa RB. Cognitive-behavioral therapy for anxiety disordered children in a clinical setting: No additional effect of a cognitive parent training. Journal of the American Academy of Child and Adolescent Psychiatry. 2003; 42:1270-1278. [PubMed: 14566163]

Nock MK, Kazdin AE, Hiripi E, Kessler RC. Lifetime prevalence, correlates, and persistence of oppositional defiant disorder: Results from the National Comorbidity Survey Replication. Journal of Child Psychology and Psychiatry. 2007; 48:703-713. [PubMed: 17593151]

Ogden T, Hagen KA. Treatment effectiveness of parent management training in Norway: A randomized controlled trial of children with conduct problems. Journal of Consulting and Clinical Psychology. 2008; 76:607-621. [PubMed: 18665689]

O’Leary EMM, Barrett P, Foermestad KW. Cognitive-behavioral family treatment for childhood obsessive-compulsive disorder: A 7-year follow-up study. Journal of Anxiety Disorders. 2009; 23:973-978. [PubMed: 19640677]

Patterson, GR. Coercive family processes. Eugene, OR: Castalia; 1982.

Patterson GR, Brodsky G. A behavior modification program for a child with multiple problem behaviors. Journal of Child Psychology and Psychiatry. 1966; 7:277-295.

Pelham, WE. Overmedicating America's children: Medication and alternatives to treating ADHD. In: Cummings, NA.; O’Donohue, W., editors. Restoring psychotherapy as the first intervention in behavioral care. New York: Ithaca Press; 2012. p. 297-326.

Pelham WE, Fabiano GA. Evidence-based psychosocial treatments for attention-deficit/hyperactivity disorder. Journal of Clinical Child and Adolescent Psychology. 2008; 37:184-214. [PubMed: 18444058]

Pettit GS, Laird RD, Dodge KA, Bates JE, Criss MM. Antecedents and behavior-problem outcomes of parental monitoring and psychological control in early adolescence. Child Development. 2001; 72:583-598. [PubMed: 11333086]

Rakow A, Forehand R, McKee L, Champion J, Fear J, Compas BE. The relation of parental guilt induction to child internalizing problems when a caregiver has a history of depression. Journal of Child and Family Studies. 2009; 18:367-377. [PubMed: 20090863]

Rakow A, Forehand R, McKee L, Roberts L, Haker K, Compas B. Parent guilt induction and child internalizing problems when a caregiver has a history of depression. Journal of Family Psychology. 2011; 25:147-151. [PubMed: 21355654]

Rapee RM. Group treatment of children with anxiety disorders: Outcome and predictors of treatment response. Australian Journal of Psychology. 2000; 52:125-129.

Rapee RM, Abbott MJ, Lyncham HJ. Bibliotherapy for children with anxiety disorders using written materials for parents: A randomized controlled trial. Journal of Consulting and Clinical Psychology. 2006; 71:436-441. [PubMed: 16822101]

Rapee, RM.; Wignall, A.; Spence, SH.; Cobham, V.; Lyneham, H. Helping your Anxious Child: A step-by-step guide for parents. 2. New Harbinger Publications; Oakland, CA: 2008. 
Reyno SM, McGrath PJ. Predictors of parent training efficacy for child externalizing behavior problem: A meta-analytic review. Journal of Child Psychology and Psychiatry. 2006; 47:99-111. [PubMed: 16405646]

Reynolds S, Wilson C, Austin J, Hooper L. Effects of psychotherapy for anxiety in children and adolescents: A meta-analytic review. Clinical Psychology Review. 2012; 32:251-262. [PubMed: 22459788]

Saavedra LM, Silverman WK, Morgan-Lopez AA, Kurtines WM. Cognitive behavioral treatment for childhood anxiety disorders: Long-term effects on anxiety and secondary disorders in young adulthood. Journal of Child Psychology and Psychiatry. 2010; 51:924-934. [PubMed: 20345838]

Schwartz OS, Dudgeon P, Sheeber LB, Yap MBH, Simmons JG, Allen NB. Parental behaviors during family interactions predict changes in depression and anxiety symptoms during adolescence. Journal of Abnormal Child Psychology. 2012; 40:59-71. [PubMed: 21789522]

Scotti JR, Morris TL, McNeil CB, Hawkins RP. DMS-IV and disorders of childhood and adolescence: Can structural criteria be made functional? Journal of Consulting and Clinical Psychology. 1996; 64:1177-1191. [PubMed: 8991304]

Serketich WJ, Dumas JE. The effectiveness of behavioral parent training to modify antisocial behavior in children: A meta-analysis. Behavior Therapy. 1996; 27:171-186.

Settipani CA, O’Neil KA, Podell JL, Beidas RS, Kendall PC. Youth anxiety and parent factors over time: Directionality of change among youth treated for anxiety. Journal of Clinical Child \& Adolescent Psychology. in press.

Shortt AL, Barrett PM, Fox TL. Evaluating the FRIENDS program: A cognitive-behavioral group treatment for anxious children and their parents. Journal of Clinical Child Psychology. 2001; 30:525-535. [PubMed: 11708240]

Silverman WK, Pina AA, Viswesvaran C. Evidence-based psychosocial treatments for phobic and anxiety disorders in children and adolescents. Journal of Clinical Child and Adolescent Psychology. 2008; 37:105-130. [PubMed: 18444055]

Silverman WK, Kurtines WM, Ginsburg GS, Weems CF, Lumpkin PW, Carmichael DH. Treating anxiety disorders in children with group cognitive-behavioral therapy: A randomized clinical trial. Journal of Consulting and Clinical Psychology. 1999a; 67:995-1003. [PubMed: 10596522]

Silverman WK, Kurtines WM, Ginsburg GS, Weems CF, Rabian F, Serafini LT. Contingency management self-control, and education support in the treatment of childhood phobic disorders: A randomized clinical trial. Journal of Consulting and Clinical Psychology. 1999b; 67:675-687. [PubMed: 10535234]

Silverman WK, Kurtines WM, Jaccard J, Pina AA. Directionality of change in youth anxiety treatment involving parents: An initial examination. Journal of Consulting and Clinical Psychology. 2009; 77:474-485. [PubMed: 19485589]

Spence SH, Donovan C, Brechman-Toussaint M. The treatment of childhood social phobia: The effectiveness of a social skills training-based, cognitive-behavioural intervention, with and without parental involvement. Journal of Child Psychology and Psychiatry. 2000; 41:713-726. [PubMed: 11039684]

Spence SH, Donovan CL, March S, Gamble A, Anderson, Kenardy J. A randomized controlled trial of online versus clinic-based CBT for adolescent anxiety. Journal of Consulting and Clinical Psychology. 2011; 79:629-642. [PubMed: 21744945]

Spence SH, Holmes JM, March S, Lipp OV. The feasibility and outcome of clinic plus internet delivery of cognitive-behavior therapy for childhood anxiety. Journal of Consulting and Clinical Psychology. 2006; 74:614-621. [PubMed: 16822117]

van der Sluis CM, van der Bruggen CO, Brechman-Toussaint ML, Thissen MAP, Bögels SM. Parentdirected cognitive behavioral therapy for young anxious children: A pilot study. Behavior Therapy. 2012; 43:583-592. [PubMed: 22697446]

van de Wiel NMH, Matthys W, Cohen-Kettenis PT, Maassen GH, Lochman JE, van Engeland H. The effectiveness of an experimental treatment when compared to care as usual depends on the type of care as usual. Behavior Modification. 2007; 31:298-312. [PubMed: 17438344]

Wahler G, Winkel GH, Peterson RF, Morrison DC. Mothers as behavior therapists for their own children. Behaviour Research and Therapy. 1965; 3:113-124. [PubMed: 5828566] 
Waters AM, Ford LA, Wharton TA, Cobham VE. Cognitive-behavioural therapy for young children with anxiety disorders: Comparison of a child + parent condition versus a parent only condition. Behaviour Research and Therapy. 2009; 47:654-662. [PubMed: 19457471]

Webster-Stratton C, Hammond M. Treating children with early-onset conduct problems: A comparison of child and parent training interventions. Journal of Consulting and Clinical Psychology. 1997; 65:93-109. [PubMed: 9103739]

Webster-Stratton C, Herman KC. The impact of parent behavior-management training on child depressive symptoms. Journal of Counseling Psychology. 2008; 55:473-484. [PubMed: 22017554]

Weisz JR, Chorpita BF, Palinkas LA, Schoenwald SK, Miranda J, Bearman SK. Research Network on Youth Mental Health. Testing standard and modular designs for psychotherapy treating depression, anxiety, and conduct problems in youth: A randomized effectiveness trial. Archives of General Psychiatry. 2012; 69:274-282.10.1001/archgenpsychiatry.2011.147 [PubMed: 22065252]

Weisz JR, Gray JS. Evidence-based psychotherapy for children and adolescents: Data from the present and a model for the future. Child and Adolescent Mental Health. 2008; 13:54-65.

Wells, KC.; Lochman, JE.; Lenhart, LA. Coping power: Parent group program. New York: Oxford University Press; 2008.

Williams SR, Kertz SJ, Schrock MD, Woodruff-Borden J. A sequential analysis of parent-child interactions in anxious and nonanxious families. Journal of Clinical Child \& Adolescent Psychology. 2012; 41:64-74. [PubMed: 22233246]

Wood JJ, Piacentini JC, Southam-Gerow M, Chu BC, Sigman M. Family cognitive behavioral therapy for child anxiety disorders. Journal of American Academy of Child and Adolescent Psychiatry. 2006; 45:314-312. 


\section{Highlights}

- Reviews effects of parent training with children's disruptive and anxiety problems.

- Parents have played a less prominent role in the treatment of children's anxiety.

- Parenting plus child interventions for children's anxiety are effective.

- Limited evidence emerges for parenting as a mediator.

- Directions for future research are delineated. 


\begin{tabular}{|c|c|c|c|}
\hline & $\begin{array}{l}\text { Intervention } \\
\text { Built Around }\end{array}$ & $\begin{array}{l}\text { Actual Role of } \\
\text { Parent in }\end{array}$ & $\begin{array}{c}\text { Primary Parent } \\
\text { Behaviors Targeted }\end{array}$ \\
\hline Trajectories & & & \\
\hline
\end{tabular}

\begin{tabular}{|c|c|c|c|c|}
\hline $\begin{array}{l}\text { Disruptive } \\
\text { Behavior }\end{array}$ & Yes & Yes & $\begin{array}{l}\text { Change behavior } \\
\text { directed toward } \\
\text { child }\end{array}$ & $\begin{array}{l}\text { Decrease coercive \& } \\
\text { increase positive } \\
\text { behavior }\end{array}$ \\
\hline Anxiety & No & No & $\begin{array}{l}\text { Varied (e.g., } \\
\text { consultant, } \\
\text { collaborator) } \\
\text { when parent is } \\
\text { included }\end{array}$ & $\begin{array}{l}\text { Increase positive } \\
\text { behavior \& decrease } \\
\text { control }\end{array}$ \\
\hline
\end{tabular}

Figure 1.

Summary of Role of Parents in the Development and Treatment of Child Disruptive and Anxiety Problems. 


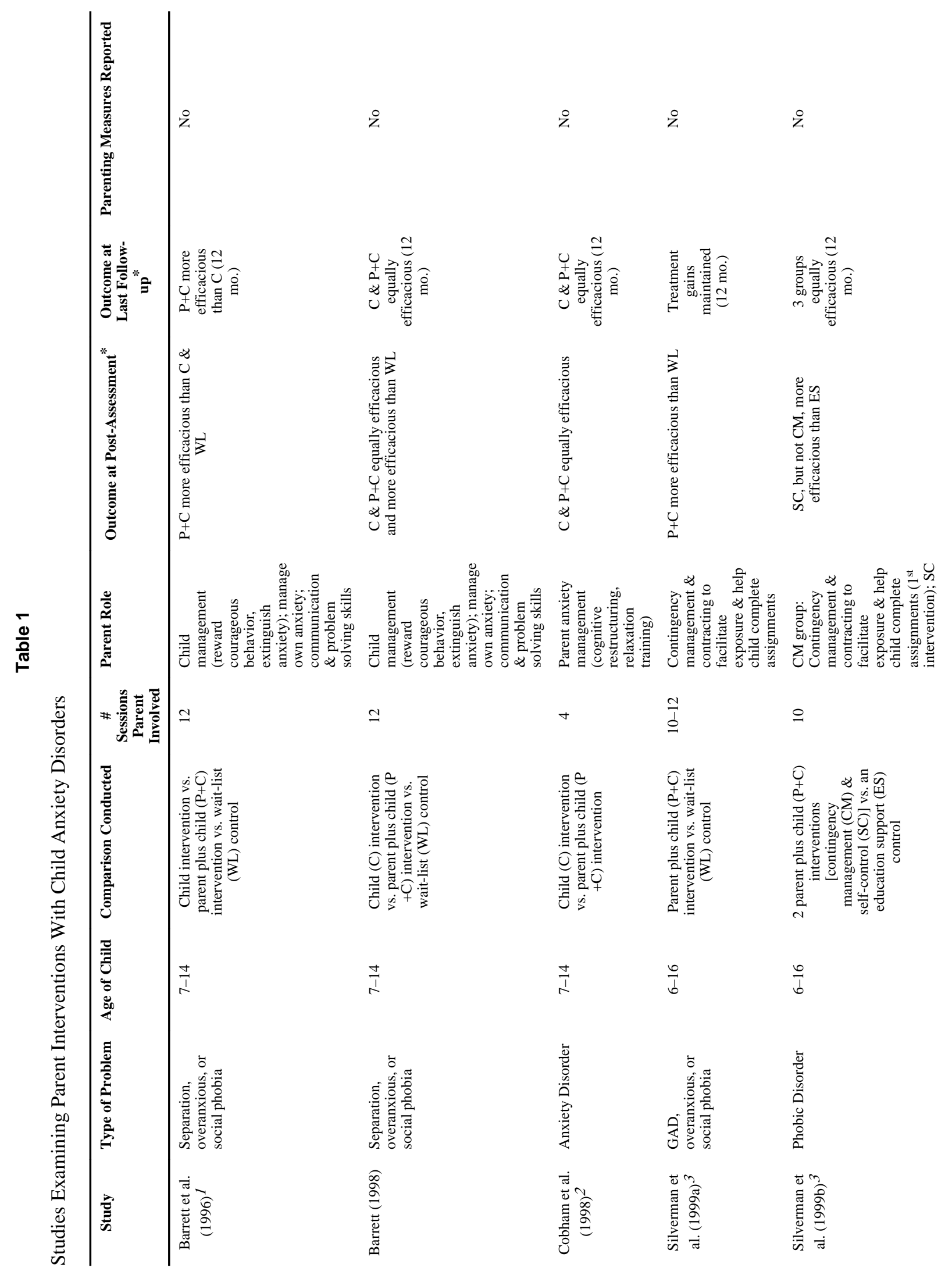




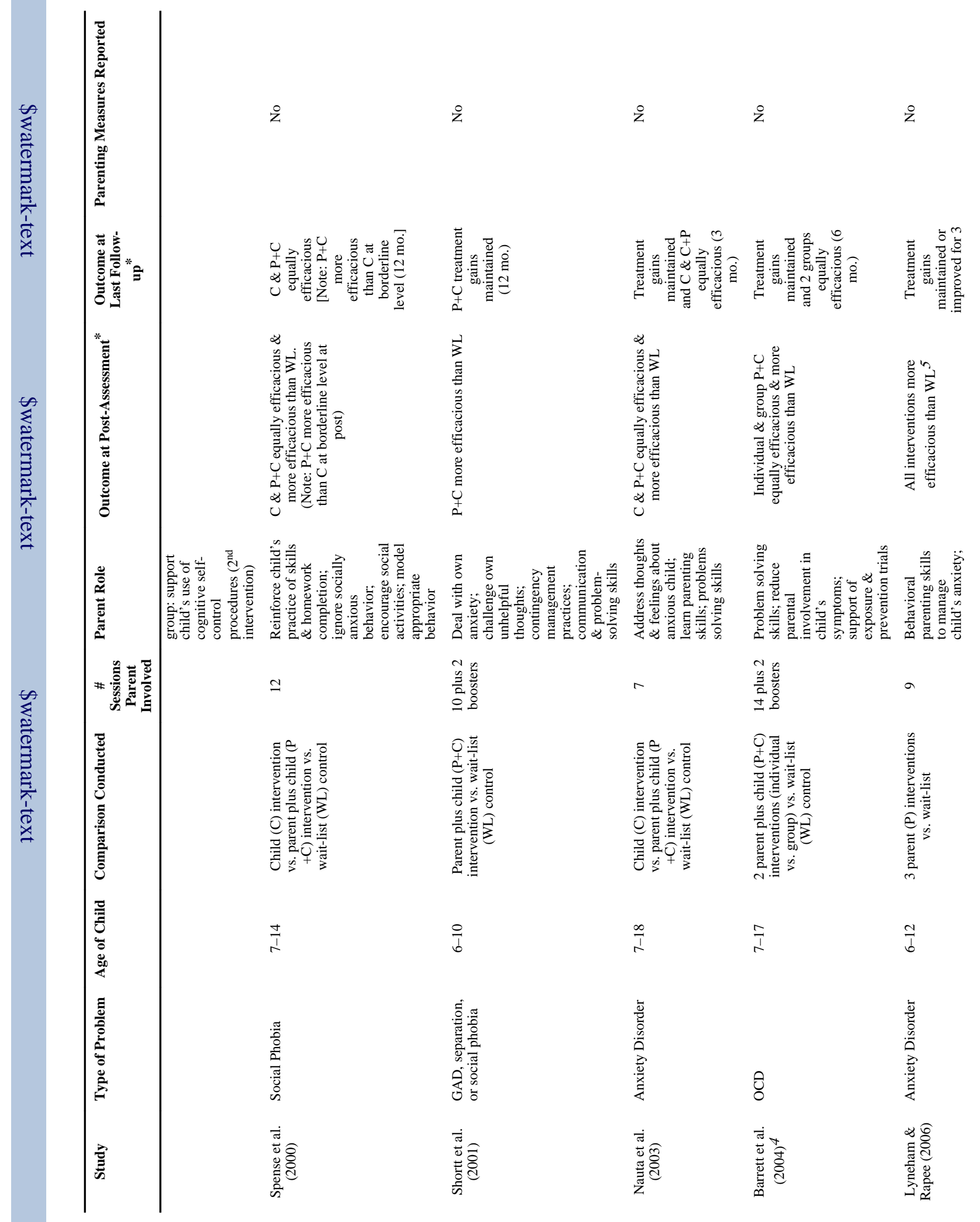




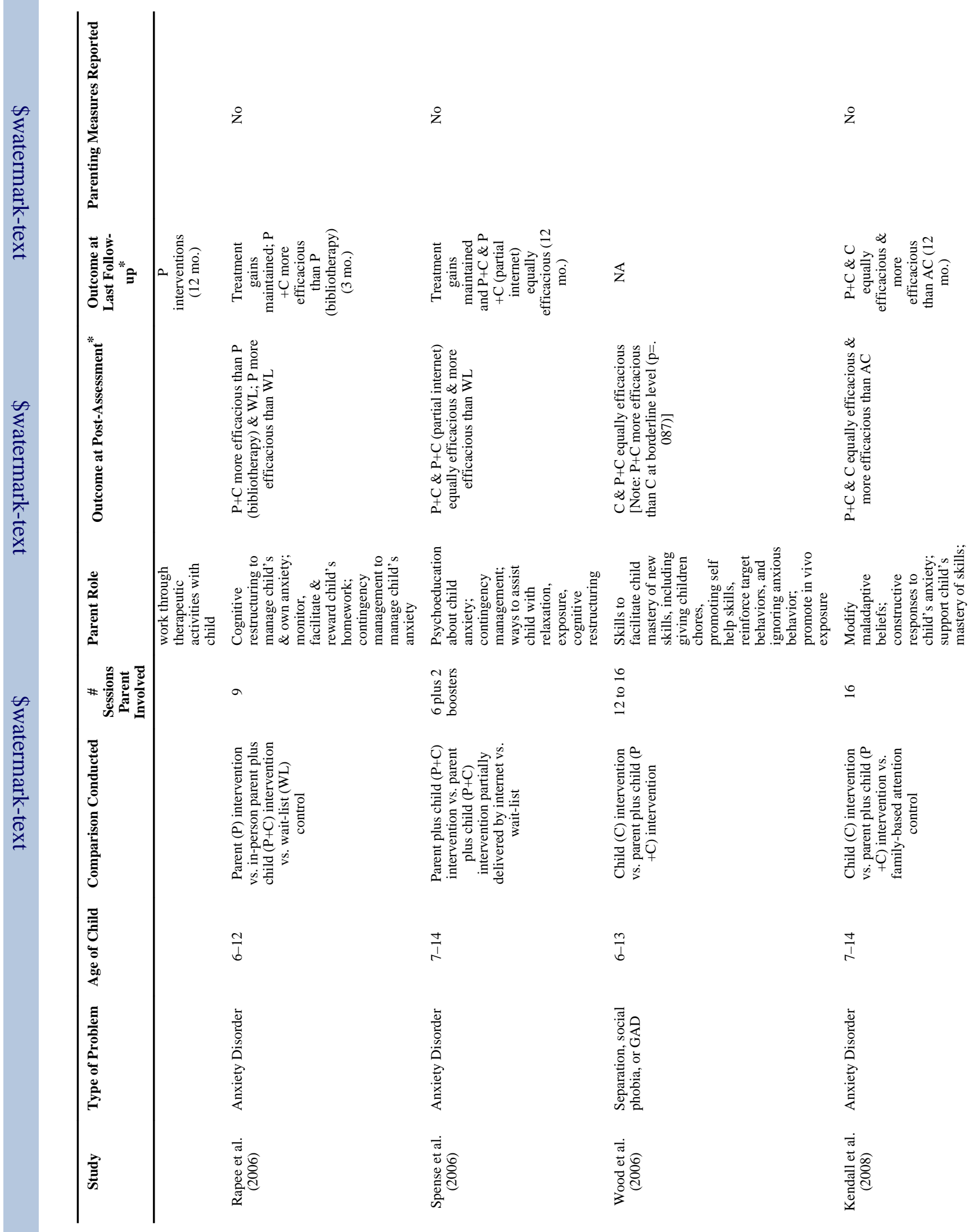




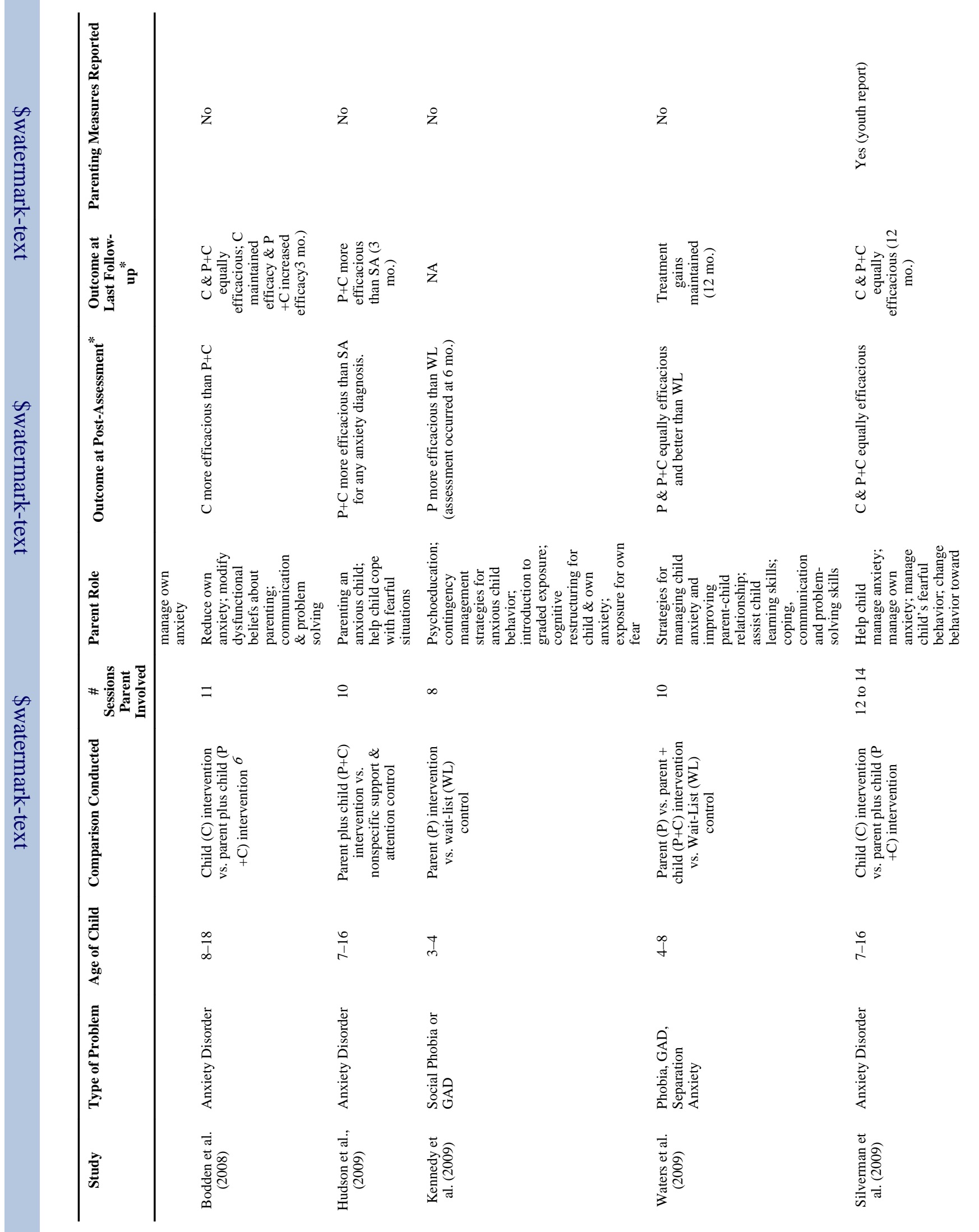


Forehand et al.

Page 28

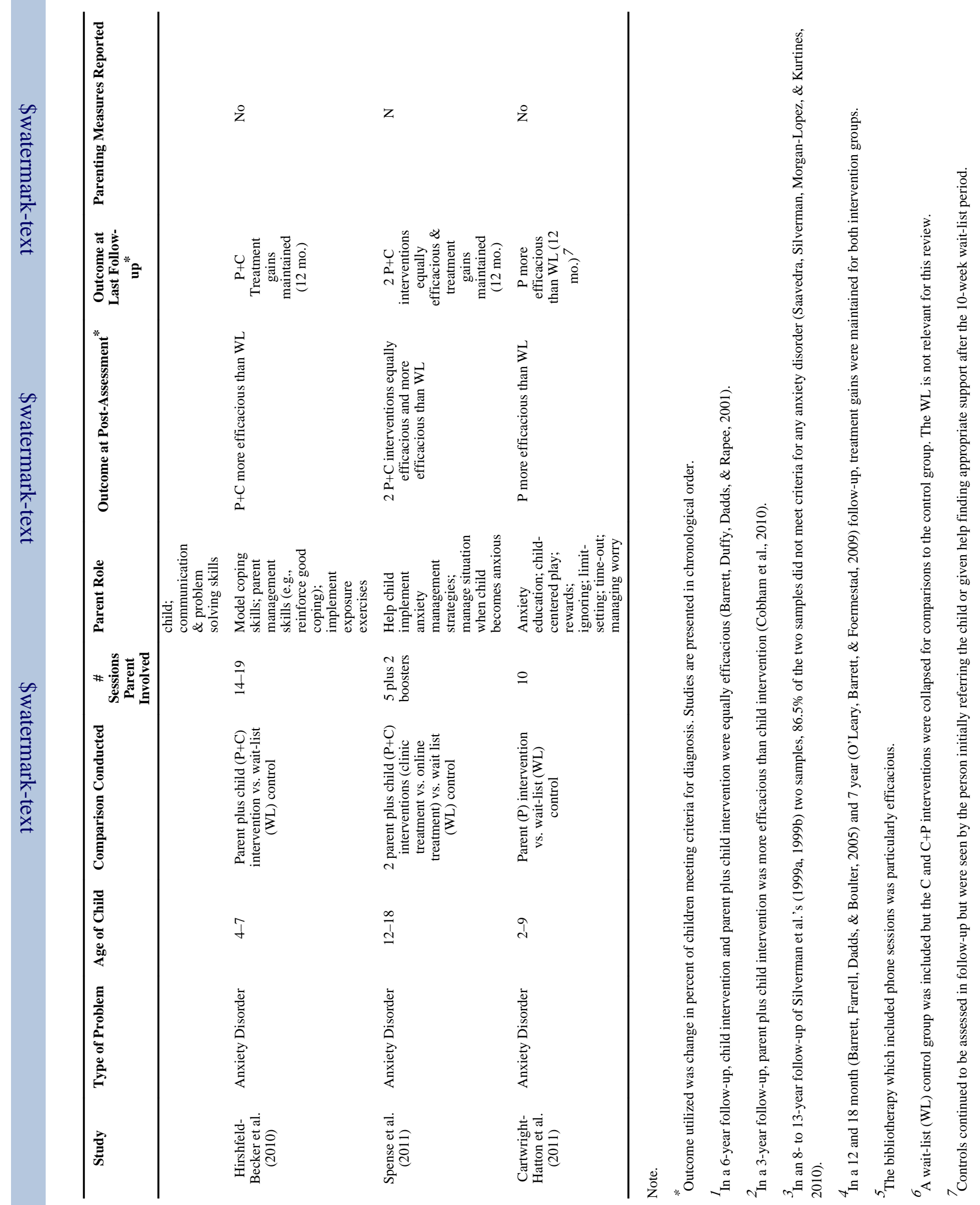

Clin Psychol Rev. Author manuscript; available in PMC 2014 February 01. 
Table 2

Summary of Individual Comparisons Across Treatment Studies of Child Anxiety

\begin{tabular}{lccc}
\hline Comparison & Yes & No & $\%$ \\
\hline Parent Intervention More Efficacious Than Control & 4 & 0 & 100 \\
Parent plus Child or Family Intervention More Efficacious than Control & 18 & 1 & 95 \\
Parent Intervention More Efficacious Than Child Intervention & 0 & 0 & 0 \\
Parent + Child Intervention More Efficacious Than Parent Intervention & 1 & 2 & 33 \\
Parent + Child Intervention More Efficacious Than Child Intervention & 1 & 7 & 13 \\
\hline
\end{tabular}




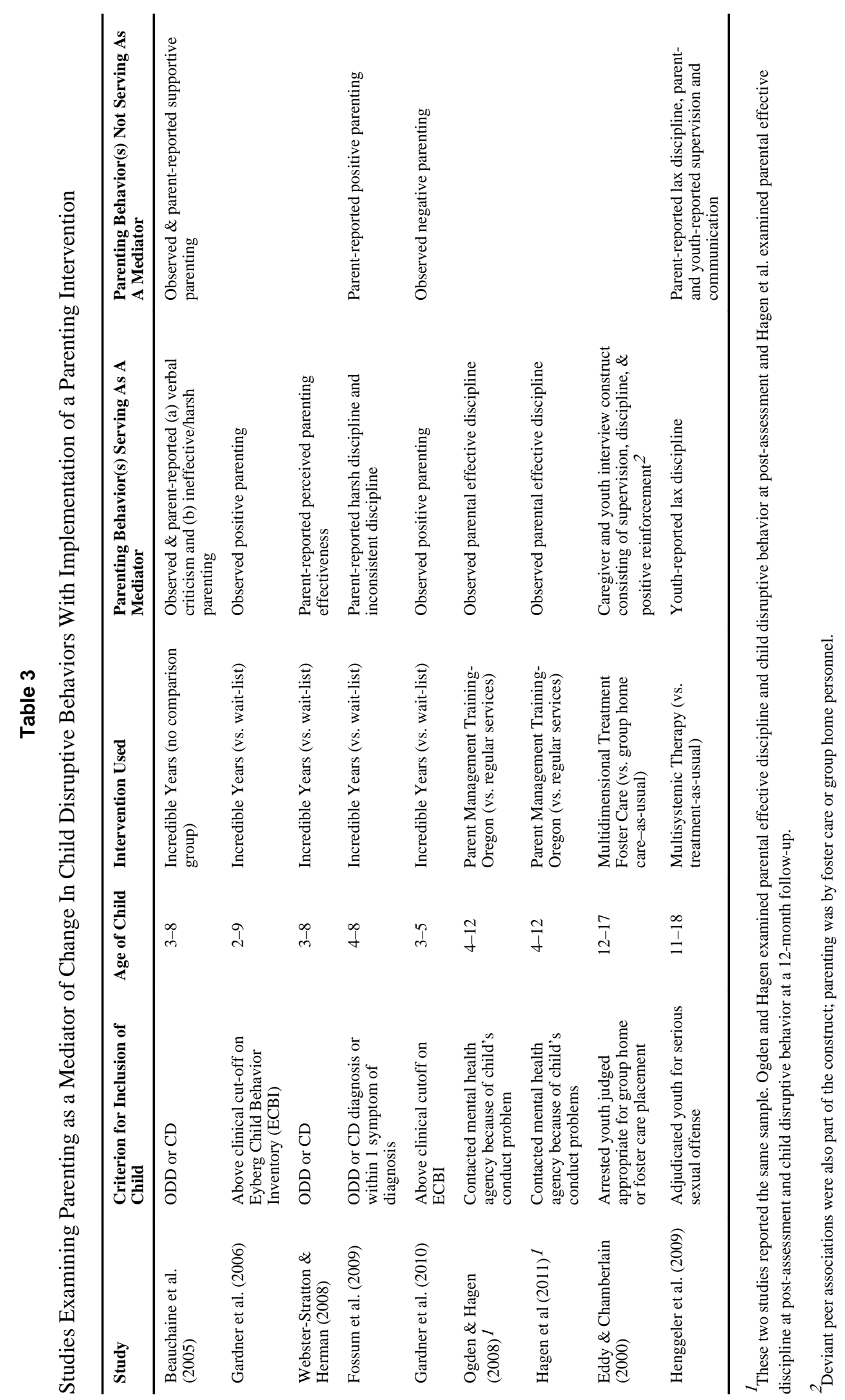

